\title{
Every Second Counts: The Race to Transplant the First Human Heart
}

D. McRae

New York, New York: G.P. Putnam's Sons, 2006, 356 pages, \$25.95

All these years later I can still see it clearly. It was an unforgettable sight. We had taken the old heart and we needed to move damn fast to fill that huge hole with a new heart. No wonder they were frightened of us then. No wonder they thought we were out of our minds.

Adrian Kantrowitz

Every year, approximately 2,500 heart transplantations are performed in the United States. Heart transplantations are such an accepted procedure in cardiology that it is not unusual to find a transplant patient having a stress test performed in the nuclear medicine department. It is well known that the first heart transplantation was performed in South Africa by Dr. Christiaan Barnard at Groote Schuur Hospital in 1967-2 years before astronauts first landed on the moon. Donald McRae's Every Second Counts: The Race to Transplant the First Human Heart retells the riveting tale of 4 surgeons, each trying to become the first to transplant a human heart.

Adapting a journalistic style of writing, the author describes the dramatic story of the race to become the first team to perform a surgical heart transplantation between one human and another. The protagonists were 3 surgical research teams in the United States, headed by Norman Shumway at Stanford, Richard Lower in Virginia, and Adrian Kantrowitz in New York, and a team in South Africa lead by Christiaan Barnard. The book follows the step-bystep struggles of each research team, commenting on each technologic and surgical innovation needed to complete the task. Ideas as simple as hypothermia to reduce damage to a donated heart had to be conceptualized.

Ethical considerations are a central theme of the book because in the 1960s, American law accepted only the absence of a heartbeat as the definition of death. The modern concept of brain death, fundamental for transplantation today, did not yet legally exist. So strong was the concept that the beating heart determined life that one of the investigators in the race, Dick Lower, was even charged with a million dollar wrongful-death lawsuit for transplanting a donor heart that had not yet stopped. Contrary to U.S. law, South Africa was unique in basing the definition of death only on the agreement of 2 physicians rather than on the cessation of any

COPYRIGHT (c) 2007 by the Society of Nuclear Medicine, Inc. DOI: 10.2967/jnumed.107.042549 vital organ. This factor was most important in leading Christiaan Barnard to success because his heart could come from an otherwise healthy body, whereas in the United States the heart had to be from someone who had died.

An important theme of this book is the political and racially tense atmosphere of South Africa, where Dr. Barnard performed his heart transplantation. Christiaan Barnard grew up in an isolated community-reviled by the white Afrikaners because his father, a Calvinist minister, preached to a "colored" church. As a boy, Christiaan learned to respect people for their character rather than because of their race. In his research on animals, he often secretly worked alongside black surgeons and anesthesiologists while officially claiming them to be no more than laboratory assistants. Dr. Barnard often stated as a surgeon that once every patient was opened up, they all bled the same color. For South Africa to be at the forefront of transplantation technology, care had to be taken with race to avoid focusing attention on apartheid rather than on medical breakthroughs.

There are humorous passages in the book. Dr. Barnard recounts a story when one day his chauffeur, who had learned quite a lot about heart transplantation by attending the lectures to which he had driven the doctor, swapped suits with him and impersonated him because Dr. Barnard was tired. Dr. Barnard sat in the back wearing the chauffeur's uniform. He was extremely impressed by how well the chauffeur lectured, until he realized that the famous Dr. Michael DeBakey, who did pioneer work in cardiology, was in the audience. Dr. DeBakey, not knowing about the impersonation, asked the chauffer a convoluted question about immunology and rejection. The chauffeur, realizing that he did not know the answer, calmly replied, "Excuse me, sir, but aren't you Dr. DeBakey from Houston? Well, Dr. DeBakey, I'm surprised that a man with your knowledge and experience could ask such a stupid question. To show you how stupid your question really is, my chauffeur at the back of the hall will answer it for you." 
The final part of the book follows how Christiaan Barnard's life changed subsequent to his success in performing the first cardiac transplantation. Overnight, Dr. Barnard became a celebrity figure, finding himself on the cover of Time magazine, whereas weeks earlier he could not even afford to buy a copy. He received invitations from famous celebrities, including a phone call from Dean Martin inviting him to stay at his Hollywood home. He was received by the Pope in Rome, spent time at President Johnson's ranch, and even dated movie stars, such as Gina Lollobrigida.

Every Second Counts is a fascinating story about the race to perform the first heart transplantation. The book has aspects of human drama including fame, glory, despair, and notoriety. We strongly recommend this book to anyone in the medical field interested in medical history, research, and ethics. 